\title{
A comparative study on the nitrogen utilization efficiency and growth rate of domestic keumgang and chokyeong wheat
}

\author{
Won Je Lee $^{1} \cdot$ Chan Young Jeong $^{1} \cdot$ Seokjin Lee $^{1} \cdot$ Chon-Sik Kang $^{2}$. $^{2}$ \\ Hojoung Lee ${ }^{1}$ (D)
}

Received: 9 January 2019 / Accepted: 15 January 2019 / Published Online: 31 March 2019

(C) The Korean Society for Applied Biological Chemistry 2019

\begin{abstract}
All countries, including Korea, are currently experiencing the effect of rapid climate change. As a result, the cultivation area of many crops including wheat is changing, or productivity is falling sharply. If enough nitrogen is present in the soil, the increase in atmospheric carbon dioxide due to the greenhouse effect can lead to increased photosynthesis of plants, resulting in increased productivity. By contrast, a low proportion of nitrogen in soil does not increase production, often leading to the use of nitrogen fertilizers to increase crop productivity: this causes serious environmental pollution due to the leakage of nitrogen fertilizers used by crops. Increasing the understanding of the molecular level of the plant nitrogen use efficiency mechanism may contribute to increased productivity of crops and reduced of environmental pollution by nitrogen. In Korea, cultivars have developed 35 kinds of wheat, such as 'keumgang' and 'Chokyeong', which can be used for specific purposes such as baking or noodles. In this study we investigate 'keumgang' and 'Chokyeong' in order to elucidate the mechanism of nitrogen use ability of wheat and contribute to the reduction of environmental pollution by providing guidelines for the proper use of nitrogenous fertilizer.
\end{abstract}

Hojoung Lee $(\square)$

E-mail: 1hojoung@korea.ac.kr

Chon-Sik Kang $(\bowtie)$

E-mail:kcs1209@korea.kr

${ }^{1}$ Department of Biosystems and Biotechnology, College of Life Sciences and Biotechnology, Korea University, Anam-dong 5-ga, Seongbuk-gu, Seoul 02841, Republic of Korea

${ }^{2}$ Crop Breeding Division, National Institute of Crop Science, RDA, Wanju 55365 , Republic of Korea

This is an Open Access article distributed under the terms of the Creative Commons Attribution Non-Commercial License (http://creativecommons. org/licenses/by-nc/3.0/) which permits unrestricted non-commercial use, distribution, and reproduction in any medium, provided the original work is properly cited.
Keywords Chokyeong ' Keumgang · Nitrogen fertilizers · Nitrogen use efficiency

\section{Introduction}

The hexaploid bread wheat, Triticum aestivum L. (AABBDD, 2n $=6 \mathrm{x}=42$ ), whoch is consumed worldwide, is a crop born as a result of natural mating between tetraploid Triticum dicoccoides (AABB, $2 \mathrm{n}=4 \mathrm{x}=28$ ) and Aegilops tauschii (DD, $2 \mathrm{n}=2 \mathrm{x}=14$ ). Bread wheat is considered to be among the very important grains for mankind, along with corn and rice [1-3]. Bread wheat accounts for 36 percent of the world's population's food consumption $[4,5]$. Global warming, which has recently become a serious environmental problem, increases the temperature of the surface every year and causes many problems in the production of foods, including wheat [6]. Recent reports suggest that the temperature rise on earth has reduced wheat productivity by up to five percent [7]. If this continues, it is predicted that wheat production will decrease by up to 50 percent over the next 10 years [8]. Faced with decreased production caused by the temperature rise in the crop cultivation environment, farmers have attempted to overcome this by using more fertilizer. Nitrogen $(\mathrm{N})$ is one of the essential nutrients for increasing plant growth and crop productivity. While vast amounts of nitrogen fertilizer are used worldwide in order to maximize crop productivity [9], only about 30-50 percent of the amount supplied to the soil is absorbed by plants, while the rest is leaked to the soil through various channels, causing serious environmental pollution and causing ecosystem imbalances [10]. Therefore, research on accommodating the growing global population's food demand and preserving the ecological environment of the earth is crucial. As part of this, we can consider the use of efficient nitrogen fertilizer in agriculture. Although it has been shown that nitrogen concentrations in the five-stage plant growth process proposed by Feeke (GS 5) winter wheat (Triticum aestivum L.) 
can be used to produce more accurate nitrogen fertilizer recommendations, a more convenient and accurate method may be needed to predict the nitrogen fertilizer needs of wheat [11]. While ensuring the proper usage of nitrogen fertilizer is important, another approach to reducing the use of nitrogen fertilizers is to improve the efficiency of nitrogen use (NUE, nitrogen use efficiency) in crops [12]. The NUE measurements of wheat and other grains are based on evaluations of crop yields for the amounts of fertilizers, performance responses to added nitrogen fertilizers, or quantifications of nitrogen fertilizer recovery rates [13]. However, NUE consists of two main components, N intake and $\mathrm{N}$ utilization efficiency, which consist of complex characteristics including many physiological processes and biochemical pathways. The main definition of NUE is based on the total $\mathrm{N}$ intake efficiency ( $\mathrm{N}$ divided by total $\mathrm{N}, \mathrm{NUpE}$ ) and $\mathrm{N}$ utilization efficiency ( $\mathrm{N}$ as a function adopted, NUtE) product $[14,15]$. In order to identify the appropriate use of NUEs related to wheat, studies carefully applying the definition of NUE traits should be carried out [13]. In this study, we examined the growth rate and nitrate concentration in the plant according to the difference of the external nitrogen content of the domestic keumgang and chokyeong wheat. These results are expected to be applicable as an evaluation factor for the appropriate fertilizer determination of nitrogen fertilizer in domestic wheat cultivation.

\section{Materials and Methods}

\section{Plant growth condition}

The two kinds of Korean wheat (Triticum aestivum L.), keumgang and Chokyeong, were compared to the low nitrogen resistance. The seeds were sterilized and treated for three days at $4{ }^{\circ} \mathrm{C}$. The MS, which has no nitrogen, was supplemented with 2 percent sugar $(\mathrm{pH}=5.7)$ and $5 \mathrm{mM}$ nitrate to make media and seeded in the following chamber conditions: $16 \mathrm{~h}$ light $/ 8 \mathrm{~h}$ dark cycle, $23{ }^{\circ} \mathrm{C}, 50$ to $55 \mathrm{~mol}$ photon $\mathrm{m} 2 \mathrm{~s} 1$ and about $70 \%$ humidity.

\section{Nitrate treatment condition}

Keumgang, Chokyeong seeds were sterilized and treated for three days at $4{ }^{\circ} \mathrm{C}$. The MS, which has no nitrogen, was supplemented with 2 percent sugar $(\mathrm{pH}=5.7)$ and $5 \mathrm{mM}$ nitrate in order to make media and seeds are germinated for about 2two days. The seedlings were treated with various low-concentration nitrates $(0$, $0.01,0.1,0.5,1,5,20 \mathrm{mM}$ ) in a nitrogen-free MS medium and raised in the following chamber conditions: $16 \mathrm{~h}$ light $/ 8 \mathrm{~h}$ dark cycle, $23{ }^{\circ} \mathrm{C}, 50$ to $55 \mathrm{~mol}$ photon $\mathrm{m} 2 \mathrm{~s} 1$ and about $70 \%$ humidity. The seedlings were treated with various low nitrate treatments in a nitrogen-free MS medium.

\section{Seeds germination analysis}

Keumgang, Chokyeong seeds were planted in an MS medium treated with $2 \%$ sugar $(\mathrm{pH} 5.7)$ and several low-concentration nitrates. After planting seeds, two to three days later, the germination rate wass calculated by analyzing the germination rate through the roots. About 50 seeds in total were used for analysis.

\section{Nitrate contents}

In order to determine nitrate content, use nine-day-old keumgang, Chokyeong samples of $100 \mathrm{mg}$ were used. The prepared samples are ground using liquid nitrogen. Then, $1 \mathrm{~mL}$ of distilled water was added to the sample and the sample was added to boiled water for 20 minutes. The mixture was then centrifuged at 13,000 rpm, $4{ }^{\circ} \mathrm{C}$ for 10 minutes. Then, 100 microliters of upper layer was transferred to a $15 \mathrm{~mL}$ tube and mixed with $400 \mathrm{~mL}$ of salicyl sulfate. The sample was then treated at room temperature for 30 minutes, then processed with $9.5 \mathrm{~mL}$ of $8 \% \mathrm{NaOH}$ solution, and cooled for five minutes at $4{ }^{\circ} \mathrm{C}$. Nitrate was measured by absorption at $410 \mathrm{~nm}$.

\section{Nitrate reductase activity measurement}

Nitrate-reduced enzyme activity and protein were analyzed as previously described $[16,17]$. Nitrate-reduced enzyme dynamics were studied using a Farrand filter fluorometer so as to measure the disappearance of NADH fluorescence and quantify the results using NADH standards. It was analyzed by measuring the increase of $\mathrm{A} 550 \mathrm{~nm} \quad(\mathrm{EMM}=21)$. The reduction of dichlorophenolindophenol was measured by replacing $1 \mathrm{~mm}$ dichlorophenolindophenol with standard analysis. The reduction of dichlorophenolindophenol was measured by replacing $1 \mathrm{~mm}$ dichlorophenolindophenol with standard analysis. The reduction of nitrate to methyl viologen, which has been reduced as an electronic donor, has been analyzed by Garrett and Nason [18]. Gluta-toxonereducing enzymes and hpoamlde dehydrogenases were analyzed in $25 \mathrm{~mm}$ potassium phosphate and $\mathrm{pH} 7.5$ by appropriate additives. At a concentration of $100 / \sim \mathrm{M}$ with $1 \mathrm{mM}$ glutathione and $1 \mathrm{~mm}$ hpoamlde, respectively, as electron receptors, all enzyme activities of pyrlene nucleotide are expressed as umts of 2 electrons equivalent $\mathrm{S}$ per minute.

\section{Results and Discussion}

Differences in germination ratio between Keumgang and Chokyeong wheat in low-concentration nitrate environment First, the prepared Keumgang (K2) and Chokyeong (K3) wheat were planted in a medium of 20,1, and $0.1 \mathrm{mM}$ nitrate. After two days of germination, when a high concentration of nitrate (20 $\mathrm{mM}$ ) was present, the germination rates of the Keumgang and the Chokyeong wheat did not significantly differ (Fig. 1). However, as the concentration of nitrate $(1,0.1 \mathrm{mM})$ decreased, the germination rate of the Keumgang increased slightly. This is thought to be a decrease in germination rate in the case of Keumgang by recognizing that it is in a stress situation, as it is in an excessive 
concentration of nitrate environment. However, Chokyeong does not seem to respond sensitively to nitrate concentrations because it does not show a significant difference in germination rate due to changes in nitrate concentration. However, the changes in weight during low-concentration nitrate treatment showed a clear difference. First, experiments were conducted in order to determine the changes in the growths of Keumgang and Chokyeong in low concentration nitrate conditions as follows. After planting Keumgang and Chokyeong seeds on a $20 \mathrm{mM}$ nitrate medium, which is a sufficient concentration for plant growth, only seeds germinated on the second day were selected and transferred to a medium with a nitrate concentration of $20,0.1 \mathrm{mM}$. Figure 2 shows the growth rate of the seedling on a $0.1 \mathrm{mM}$ nitrate medium and the growth rate of the plant on the first, third, and fifth days to the $20 \mathrm{mM}$ nitrate medium (100\% standard: growth rate in a 20 $\mathrm{mm}$ nitrate medium). Overall, the growth rate of Keumgang was lower than that of $20 \mathrm{mM}$ nitrate medium. By contrast, in the case of Chokyeong, for three days and five days, there was better growth in $0.1 \mathrm{mM}$ nitrate condition than in $20 \mathrm{mM}$ nitrate condition. As a result, it can be interpreted that with lower nitrate concentrations, Keumgang showed lower growth while Chokyeong grew healthier.

\section{Growth Differences between Keumgang and Chokyeong wheat in Nitrate Deficiency}

In the previous experiment, we found differences in germination and weight between Keumgang and Chokyeong wheat depending on the nitrate concentration difference (Figs. 1, 2). In order to determine why Chokyeong wheat grows better in low-concentration nitrate conditions, we first decided to investigate the content of nitrate accumulated in these wheats. Following germination, the Keumgang and Chokyeong wheat were grown at a sufficient concentration of nitrate medium $(20 \mathrm{mM})$ for five days, then the same size of seedlings were selected and transferred to a nitratedeficient medium. After being grown for one day and two days in a nitrate deficiency medium, the leaves samples of about $120 \mathrm{mg}$ were collected. The results of each nitrate content measurement showed that the Keumgang accumulated higher nitrate contents than the Chokyeong in the first and second days of nitrate deficiency (Fig. 3). Generally, it was assumed that high nitrate content would lead to better growth than low-concentration nitrate conditions, but the results were reversed. In order to more accurately confirm the growth difference, we observed changes in the growth characteristics of Keumgang and Chokyeong wheat under subdivided low concentrations of nitrate conditions. In order to test this, we planted Keumgang and Chokyeong wheat on a sufficient nitrate medium of $20 \mathrm{mM}$, then transferred them to 20 , $0.1,0.01 \mathrm{mM}$ nitrate media. Two weeks later, the difference in growth was confirmed. In high-concentration nitrate conditions, the Keumgang appears to grow slightly better than Chokyeong wheat (Fig. 4). However, when the low concentration nitrate 0.1 and $0.01 \mathrm{mM}$ were treated, the Chokyeong was larger than the

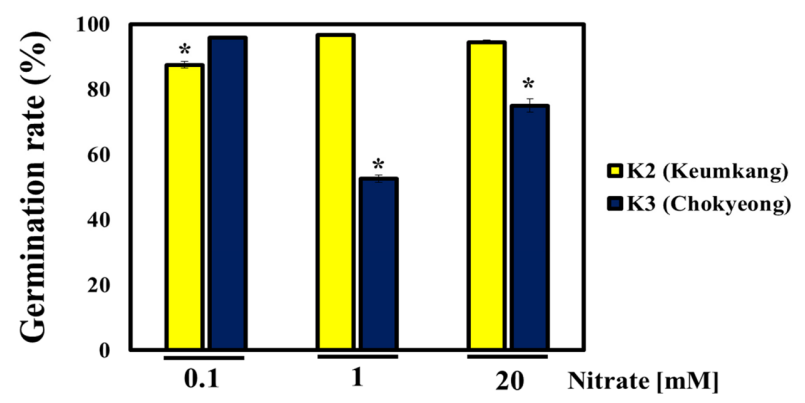

Fig. 1 Germination rate of keumgang, chokyeong .Germination rate of $\mathrm{K} 2$ (keumgang) and K3 (chokyeong) wheat in medium with nitrate concentration of $0.1,1,20 \mathrm{mM}$. After planting the seeds, the number of seeds appearing with roots after two days was quantified

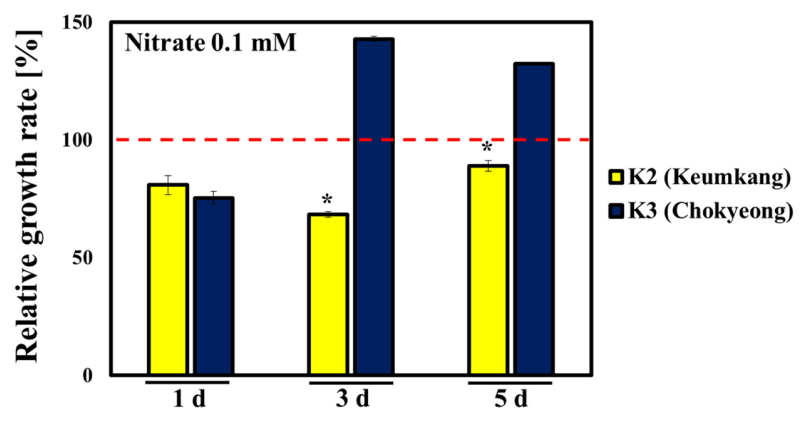

Days of treatment

Fig. 2 Relative growth rate of keumgang, chokyeong. K2 (keumgang) and $\mathrm{K} 3$ (chokyeong) which were raised for two days in solid medium of $20 \mathrm{mM}$ of nitrate were transferred to $0.1,20 \mathrm{mM}$ nitrate medium, and their growth rates were analyzed after one, three, and five days. Each point of data showed the growth rate at the $0.1 \mathrm{mM}$ for the growth rate in the $20 \mathrm{mM}$ nitrate medium

Keumgang. In other words, Keumgang showed a lower growth performance with the lower nitrate concentration, while the Chokyeong showed a healthier growth than the Keumgang. It is presumed that Chokyeong wheat has a molecular mechanism to adapt well to low concentration nitrate conditions unlike Keumgang.

\section{Differences in nitrate contents during low-concentration nitrate treatment}

After confirming that the growth difference between Keumgang and Chokyeong wheat occurs in low-concentration nitrate treatment conditions, we have confirmed the nitrate accumulation of these types of wheat in low-concentration nitrate treatment conditions. For three days, the Keumgang and Chokyeong seedlings raised in a $20 \mathrm{mM}$ nitrate medium were transferred to a low concentration nitrate $0,0.5 \mathrm{mM}$ and normal concentration nitrate $5 \mathrm{mM}$ liquid medium for seven more days. As a result, the Keumgang showed a higher nitrate accumulation than the Chokyeong at 0 and $5 \mathrm{mM}$ and there was no significant difference between the two at $0.05 \mathrm{mM}$ of nitrate (Fig. 5). The results were 


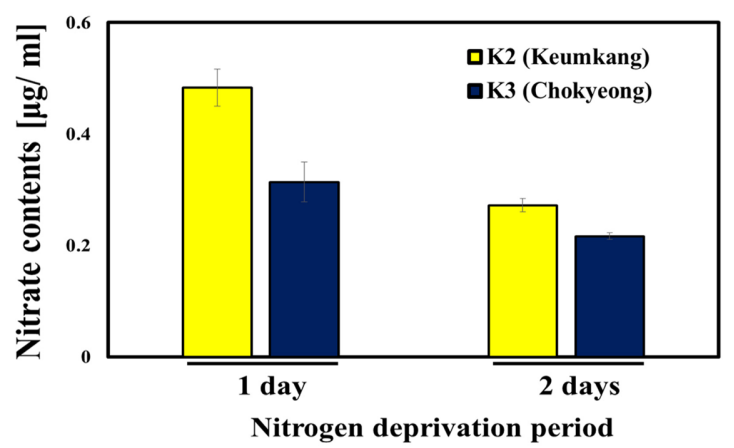

Fig. 3 Nitrate contents of keumgang, chokyeong in nitrogen deprivation. After five days of growing K2 (keumgang) and K3 (chokyeong) wheat in a solid medium containing $20 \mathrm{mM}$ of nitrate, the seedlings were transferred to nitrate-deplete medium. The nitrate contents were measured by grinding the seedlings (about $120 \mathrm{mg}$ ) raised for one or two days in nitrate deprivation
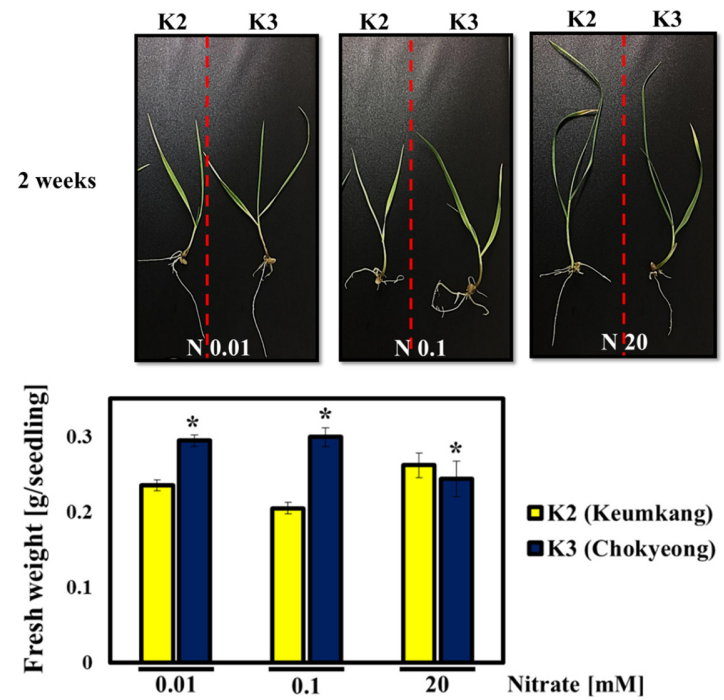

Fig. 4 Fresh weight of keumgang, chokyeong in low nitrogen conditions. Two days after seeding of K2 (keumgang) and K3 (chokyeong) on 20 $\mathrm{mM}$ nitrate medium, each seedling was transferred to $0.01,0.1$, and 20 $\mathrm{mM}$ medium of nitrate. Two weeks later, the growth performance was confirmed and quantified

different from our predictions, so we wanted to further investigate the reasons for this. Nitrate is converted to nitrite by the nitratereductase enzyme, then used in the amino acid synthesis process. Even though Chokyeong wheat accumulates less nitrate than Keumgang, it can be assumed that the nitrate-reductase enzymes activity in Chokyeong can be more effective than the Keumgang in low-concentration nitrate conditions, although the amount of nitrate accumulated in Chokyeong is less than that of Keumgang. In order to test this assumption, we found that the activity of nitrate-reductase in Keumgang and Chokyeong samples, which were treated in the same way as Fig. 5, showed that Chokyeong had a much higher activity of nitrate-reductase than Keumgang at all concentrations of $0,0.5$, and $5 \mathrm{mM}$ (Fig. 6). Through this, the

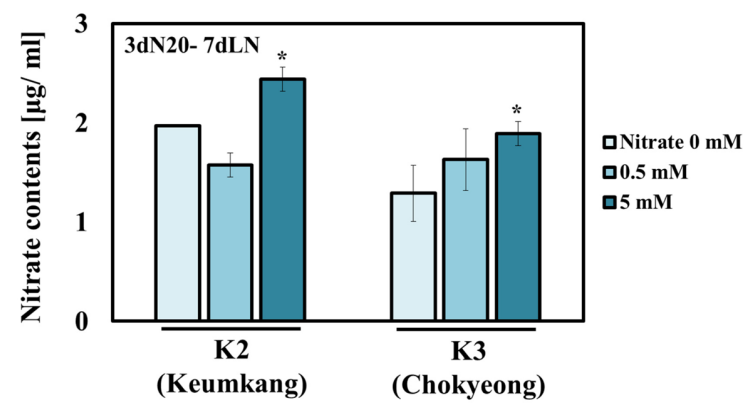

Fig. 5 Nitrate contents of keumgang, chokyeong in low nitrogen conditions. K2 (keumgang) and K3 (chokyeong) seedlings raised in a 20 $\mathrm{mM}$ nitrate medium for three days after germination were transferred to low concentration nitrate $0,0.5$, and $5 \mathrm{mM}$ liquid medium for seven days, and the nitrate contents were measured

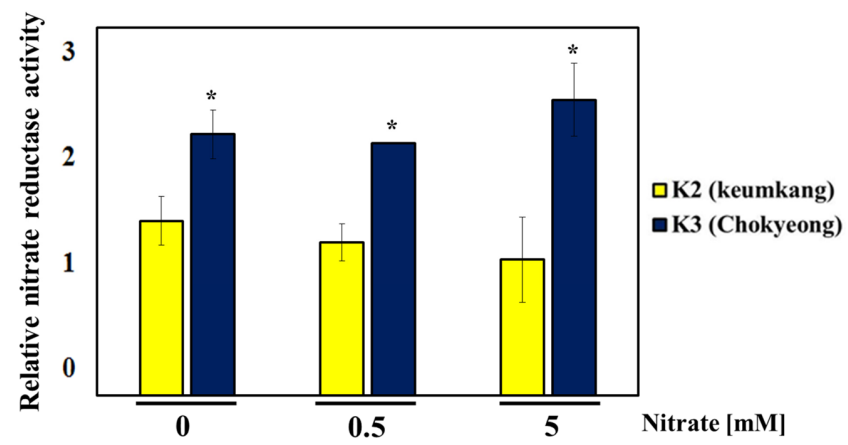

Fig. 6 Relative nitrate reductase activity of keumgang, chokyeong in low nitrogen conditions. K2 (keumgang) and K3 (chokyeong) seedlings raised in a $20 \mathrm{mM}$ nitrate medium for three days after germination were transferred to low concentration nitrate $0,0.5$, and $5 \mathrm{mM}$ liquid medium for seven days, then the activity of nitrate reductase enzyme was measured

nitric acid assimilation process will also become more active in Chokyeong, producing more DNA and amino acids and leading to increased growth. Therefore, it can be concluded that the fact that Chokyeong grows better than Keumgang in low concentration nitrate conditions is not a simple increase in nitrogen content but an increase in the activity of nitrogen reductase enzyme.

Due to the steady demand for food, feed, fuel, and textiles, agriculture around the world is becoming an increasingly important business. According to the United Nations Food and Agriculture Organization, grain production is expected to increase by 60 percent from 2000 to 2050 , and the use of synthetic fertilizers is expected to increase sharply in the future [19]. By 2030, about 69 million tons of synthetic fertilizers are expected to be consumed worldwide, of which nitrogen $(\mathrm{N})$ fertilizer is expected to account for $67 \%$ [20]. The excessive consumption of synthetic fertilizers can cause serious problems such as high cost, energy resource depletion, and environmental pollution (GHG emissions and $\mathrm{N}$ leaching) associated with their production. In order to solve this problem, we investigated the growth efficiency of low nitrogen conditions using domestic wheat varieties, Keumgang and 
Chokyeong, and confirmed that Chokyeong is more efficient in nitrogen use than Keumgang. Understanding the molecular level mechanisms of these two varieties with different nitrogen efficiencies will be a very useful study in the future.

Acknowledgment This work was supported by the National Institute of Crop Science, Rural Development Administration, Republic of Korea [grant number PJ012496012018].

\section{References}

1. Yang W, Liu D, Li J, Zhang L, Wei H, Hu X, Zou Y (2009) Synthetic hexaploid wheat and its utilization for wheat genetic improvement in China. JGG 36(9): 539-546

2. Sharma D, Singh R, Rane J, Gupta VK, Mamrutha HM, Tiwari R (2016) Mapping quantitative trait loci associated with grain filling duration and grain number under terminal heat stress in bread wheat (Triticum aestivum L.). Plant Breeding 135(5): 538-545

3. Matsuoka Y (2011) Evolution of polyploid Triticum wheats under cultivation: the role of domestication, natural hybridization and allopolyploid speciation in their diversification. Plant Cell Physiol 52(5): $750-764$

4. Cossani CM, Reynolds MP (2012) Physiological traits for improving heat tolerance in wheat. Plant Physiol 160(4): 1710-1718

5. Prerna A, Kumar A, Sengar RS (2013) Evaluation of heat and drought tolerance of wheat cultivars through physiological, biochemical and molecular approaches. Res J Agric Sci 4: 139-145

6. Talukder ASMHM, McDonald GK, Gill GS (2014) Effect of short-term heat stress prior to flowering and early grain set on the grain yield of wheat. Field Crops Research 160: 54-63

7. Lobell DB, Schlenker W, Costa-Roberts J (2011) Climate trends and global crop production since 1980. Sci 1204531
8. International Food Policy Research Institute (IFPRI) IFPRI Annual Report 2009, 2010, http://ebrary.ifpri.org/cdm/ref/collection/p15738coll2/id/6954. (Retrieved May 10, 2017)

9. Nosengo N (2003) Fertilized to death, Nat. 425 894-895

10. Garnett T, Conn V, Kaiser BN (2009) Root based approaches to improving nitrogen use efficiency in plants. Plant Cell Physiol 32(9): 1272-1283

11. Fox RH, Piekielek WP, Macneal KM (1994) Using a chlorophyll meter to predict nitrogen fertilizer needs of winter wheat. Commun Soil Sci Plant Anal 25(3-4): 171-181

12. Yu LH, Wu J, Tang H, Yuan Y, Wang SM, Wang YP, Xiang CB (2016) Overexpression of Arabidopsis NLP7 improves plant growth under both nitrogen-limiting and-sufficient conditions by enhancing nitrogen and carbon assimilation. Sci Rep 6: 27795

13. Hawkesford MJ (2017) Genetic variation in traits for nitrogen use efficiency in wheat. J Exp Bot 68(10): 2627-2632

14. Moll RH, Kamprath EJ, Jackson WA (1982) Analysis and interpretation of factors which contribute to efficiency of nitrogen utilization 1. Agron J 74(3): 562-564

15. Barraclough PB, Howarth JR, Jones J, Lopez-Bellido R, Parmar S, Shepherd CE, Hawkesford MJ (2010) Nitrogen efficiency of wheat: genotypic and environmental variation and prospects for improvement. Eur J Agron 33(1): 1-11

16. Smarrelli Jr Jhon, Campbell WH (1979) NADH dehydrogenase activity of higher plant nitrate reductase (NADH). Plant Sci Lett 16(2-3): 139147

17. Campbell WH, Smarrelli J (1978) Purification and kinetics of higher plant NADH: nitrate reductase. Plant Physiology 61(4): 611-616

18. Garrett RH, Nason A (1969) Further purification and properties of Neurospora nitrate reductase. J Bio Chem 244(11): 2870-2882

19. Food and Agriculture Organization of the United Nations-FAO. World Agriculture: towards 2030/2050. Rome: FAO; 2006. Available: http:// www.fao.org/economic/esa/esag/en/. Accessed 4 October 2014

20. Tenkorang F, Lowenberg-DeBoer J (2009) Forecasting long-term global fertilizer demand. Nutr Cycl agroecosys 83(3): 233 